\title{
VARIABILITY OF RAINFALL OVER THE COASTAL AREA IN BANGLADESH BY USING CLIMATE MODEL
}

\author{
SHAHANA ISLAM ${ }^{1}$, MD. MONIRUZZAMAN ${ }^{1} *$ AND M. A. MANNAN ${ }^{2}$ \\ ${ }^{I}$ Department of Geography and Environment, Jagannath University, \\ Dhaka-1100, Bangladesh \\ ${ }^{2}$ Bangladesh Meteorological Department, Agargaon, \\ Dhaka- 1207, Bangladesh
}

\begin{abstract}
The study attempt to understand the variability of rainfall by looking into the previous and future climate of the coastal area in Bangladesh from 1850 to 2100 by using the climate model (CMCC-CM- the Centro Euro-Mediterraneo Sui Cambiamenti Climatici Climate Model) of the Fifth Assessment Report (AR5) of the Intergovernmental Panel on Climate Change (IPCC). Rainfall data were collected from CMCC-CM by R programming for two GHGs emission scenarios (RCP 4.5 and RCP 8.5) referred to as 'Representative Concentration Pathways (RCPs)'. The analysis has been conducted based on four seasons and an annual basis by plotting model data in MS Excel and R programming. The model shows that the average annual rainfall will increase from $1055.6 \mathrm{~mm}$ (during 1850-1900) to $1368.1 \mathrm{~mm}$ (during 2051-2100) for RCP 4.5 while it will reach $1569.7 \mathrm{~mm}$ (during 2050-2100) for RCP 8.5. Rainfall is also increasing for all seasons except winter. In winter season, the average rainfall will increase from $35.37 \mathrm{~mm}$ (during 1850-1900) to $41.75 \mathrm{~mm}$ (during 2051-2100) for RCP 4.5, where it will decrease from $35.37 \mathrm{~mm}$ (during 1850-1900) to $22.55 \mathrm{~mm}$ (during 2051-2100) for RCP 8.5 in the study area. The increasing and decreasing trend are more in high GHGs emission scenarios than in the medium, which will be alarming. Accordingly, this projection will be helpful to understand the adverse impacts of climatic elements and take short and long-term planning of decision-makers in that area.
\end{abstract}

Key words: Climate model, Rainfall variability, RCP, Coastal area.

\section{Introduction}

The Fifth Assessment Report (AR5) of the Intergovernmental Panel on Climate Change (IPCC) allusions that the earth's temperature increased by $0.85^{\circ} \mathrm{C}$ from 1880 to 2012 . As well, every successive decade has been warmer than the previous one for each of the recent three decades (Stocker et al. 2014). The long-term change in average weather conditions is climate change, whose main elements or variables are temperature and rainfall (Rahman et al. 2015). Continuing warming of the world is a result of climate change, by which the population can become more sufferer (Harmeling 2008). Developing countries have been experiencing intense outcomes by extreme weather

*Corresponding author: E-mail: mdmoniruzzaman_bd@yahoo.com 
events which are expected from global warming. Projections by the IPCC and the World Meteorological Organization suggest increasing in the frequencies and intensities of climate extremes in the 21 st century.

IPCC has recognized South Asia as the most vulnerable region globally (Yousuf 2016). As a developing country, Bangladesh is one of the major climate-vulnerable countries of the world due to its geographical arrangement and its least capacity to address the devastating impacts that are occurred by climate change (Yousuf 2016; Bhuyan et al. 2018). Various climate change issues in Bangladesh, such as cyclones, riverbank erosion, floods, coastal flash floods, lower level of groundwater, drought, increasing salinity, land erosion, water logging which have increased the vulnerability for Bangladesh's people and the coastal communities (Moniruzzaman 2012; Titumir and Basak 2012) that is onethird of the country's total area (Ministry of Water Resources 2005). So, many populations of the coastal zone are relatively more vulnerable than any part of the country since more than half of them are poor and landless (Bhuyan et al. 2018). Besides, manmade global climate change and associated sea level rise can have a major adverse penalty for coastal ecosystems.

To overcome the uncertainties as well as to apprehend the magnitude and direction of future changes, it is necessary to evaluate the spatial and temporal changes of past climate and future prediction. The previous study noticed that high temperatures, heavy rainfall, and seasonal variation are the unique characteristics that distinguish the climate of Bangladesh from that of other tropical regions (Partal and Kahya 2006). The country's yearly average maximum temperature from 1953 to 2011 increased by $0.52^{\circ} \mathrm{C}$ at a rate of $0.01^{\circ} \mathrm{C}$ per year (Yousuf 2016). It has been observed that the annual rainfall and daily mean temperature of Bangladesh have increased by an amount of $5.2 \mathrm{~mm} /$ year and $0.9^{\circ} \mathrm{C} /$ decade respectively (Shahid 2011). As well, it is well established that the rainfall is changing on both the global (Hulme et al. 1998; Lambert et al. 2003; Dore 2005) and the regional scales (Rodriguez-Puebla et al. 1998; Gemmer et al. 2004; Kayano and Sansigolo 2009) due to global warming. The rainfall-dominated climate of Bangladesh receives the heaviest rainfall in the world. Heavy rainfall in the monsoon of 2007, together with the onset of flooding by Himalayan-fed Rivers, resulted in a severe flood in Bangladesh which affected more than 9 million people in more than half of the districts of the country (Shahid 2010). Shahid (2010) also identified a significant increase of annual and pre-monsoon rainfall in Bangladesh from 1958 to 2007, and substantial changes in most extreme rainfall indices are observed in Northwest Bangladesh.

On the other side, climate models are the foremost used comprehensive tools to develop future climate change projections. The new sets of climate model output become 
available for the IPCC fifth assessment report (AR5), which are also known as the CMIP5 (5th Phase Coupled Model Inter-comparison Project) multi-model dataset (Stocker et al. 2014). According to MPI-ESM-LR (CMIP5) model data, the future average temperature in north-western region will be increased at a rate of $1.62^{\circ} \mathrm{C}$ during the period 2040-2100 (Bhuyan et al. 2018). Another model study by Haque et al. (1992) indicated that the average increase in temperature would be $1.3^{\circ} \mathrm{C}$ and $1.5^{\circ} \mathrm{C}$ for the projected years of 2030 and 2075, respectively. Projections are made for rainfall in Bangladesh by Regional Climate Model (RegCM) is about $+35 \%$ for the monsoon season (JJAS), $-67 \%$ for pre-monsoon (MAM), $-12 \%$ for post-monsoon (ON), 107\% for winter (DJF) for 2050 and an average rainfall may be less by more than $50 \%$ for all seasons for the year 2060. Moreover, the model simulates more rain than observation the over central and southeastern part of Bangladesh (Mannan et al. 2018). Similarly, mean surface air temperature in different months is projected at about $(0.5-2.1)^{\circ} \mathrm{C}$ and $(0.9-3.5){ }^{\circ} \mathrm{C}$ for the years 2050 and 2060, respectively (Rahman et al. 2012). However, there have some differences between the values of observation and model data (Islam et al. 2019).

But comparatively few studies have been done on future climate from model predictions in Bangladesh. These are based on atmospheric and coupled atmospheric oceanic general circulation models (GCM), and regional climate models. Therefore, the climate change studies of climatic variables using different models or tests to estimate future projections and uncertainties over the coastal regions of Bangladesh are urgently necessary. So, the study attempts to understand rainfall variability by looking into the previous and future climate from 1850 to 2100 using the climate model (CMCC-CM- The Centro EuroMediterraneo Sui Cambiamenti Climatici Climate Model) of the coastal areas in Bangladesh. Model data were cracked and collected by $\mathrm{R}$ programming. A basic statistical method was used to understand the variability of rainfall by annual and seasonal analysis over the coastal area in Bangladesh.

\section{Materials and Methods}

Study Area: According to PDO-ICZMP (Project Development Office-Integrated Coastal Zone Management Project), 2003, the coastal areas of Bangladesh (Fig. 1) are classified by 19 coastal districts (147 Upazilas), where a total of 48 Upazilas in 12 districts are exposed to the sea and or lower estuaries, are defined as the exposed coast, and the remaining 99 Upazilas of the coastal districts are termed interior coast (Uddin and Kaudstaal 2003; Parvin et al. 2010). This $711 \mathrm{~km}$ long coastline consists of a vast 
network of river systems draining the vast flow of the Ganges-Brahmaputra-Meghna River system.

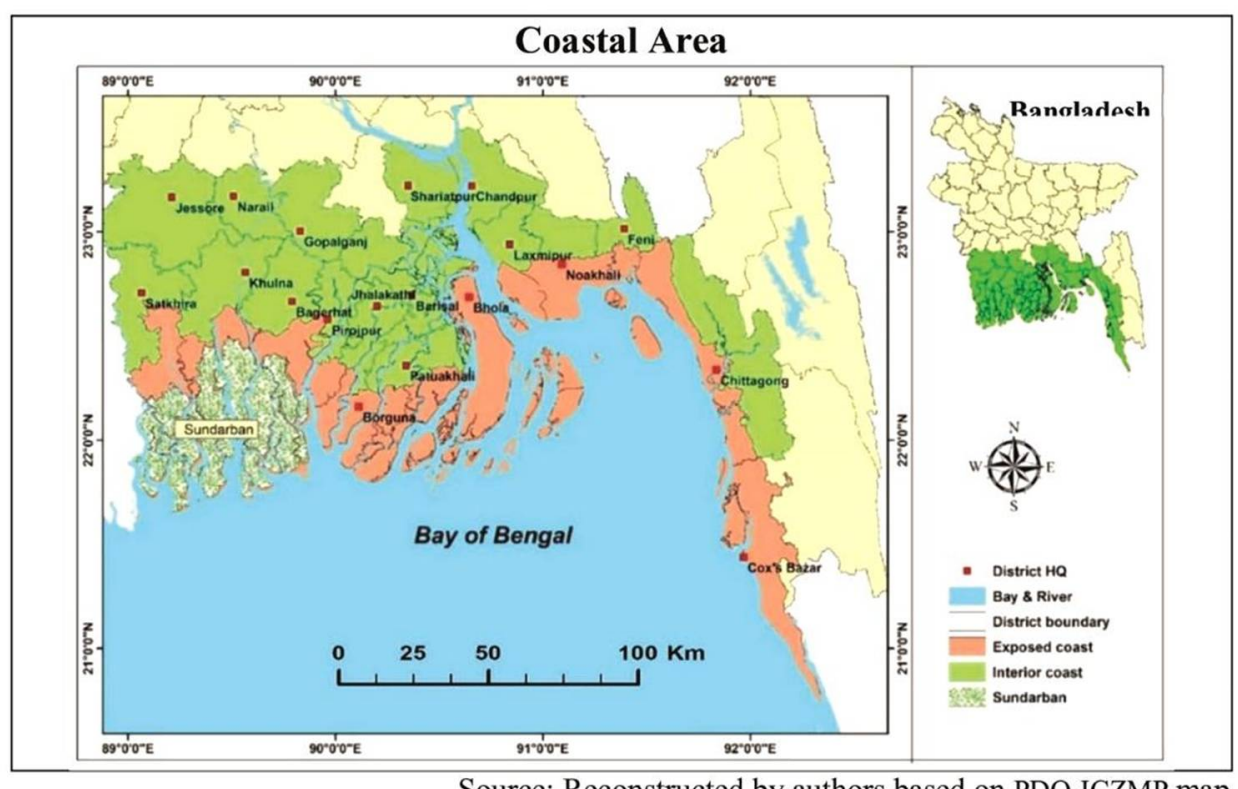

Source: Reconstructed by authors based on PDO-ICZMP map

Fig. 1. Location of Study Area.

Data Source and Analysis: Rainfall data of the coastal area of Bangladesh were collected from a general circulation model (CMCC-CM) of the 5th Phase Coupled Model Intercomparison Project (CMIP5) within IPCC during the period of 1850 to 2100 where historical data have been divided into 1850 to 2005 and future data is divided into 2006 to 2100 within four different emission scenarios. CMIP5 has many different models, and every model has different surface variables data. Again, a study of Climatic Change (2011) has shown that Representative Concentration Pathways (RCPs), a set of four new emission scenarios (RCP 2.6, RCP 4.5, RCP 6.0 and RCP 8.5) developed as an appropriate approach for investigations of future climatic conditions (Van Vuuren et al. 2011). As southern coastal Bangladesh is a small region, we have been trying to use RCP 4.5 (medium stabilization scenarios of greenhouse gas emission) and RCP 8.5 (very high baseline emission scenarios) based model for looking into the previous climate and for future climate. According to literature, data availability and data resolutions, the selected model (CMCC-CM) of CMIP5 was used (Table 1). 
Table 1. Detail climate model was used to project climate change scenarios in the study basin.

\begin{tabular}{ll}
\hline Name of GCM & $\begin{array}{l}\text { CMCC-CM (The Centro Euro-Mediterraneo sui Cambiamenti } \\
\text { Climatici Climate Model) }\end{array}$ \\
Research Center & The Euro-Mediterranean Centre on Climate Change, Italy \\
Spatial Resolutions $\left(^{\circ}\right)$ & $\begin{array}{l}\text { X axis: whole world in } 4800.75^{\circ} \text { steps } \\
\text { Y axis: Gaussian grid with } 2400.75^{\circ} \text { steps }\end{array}$ \\
Forcing & Nat (natural forcing), Ant (anthropogenic forcing), GHG (well- \\
& mixed greenhouse gases), SA (anthropogenic sulfate aerosol), \\
& TO (tropospheric ozone), Sl (solar irradiance) \\
Emission Scenarios & RCP 2.6, RCP 4.5, RCP 6 and RCP 8.5 \\
Frequency & Month \\
Time Historical & 1850 - 2005 \\
Span $\quad$ RCP 2.6, RCP 4.5, & 2006 - 2100 \\
$\quad$ RCP 6 and RCP 8.5 & \\
\hline
\end{tabular}

Source: KNMI- Koninklijk Nederlands Meteorologisch Instituut 2020

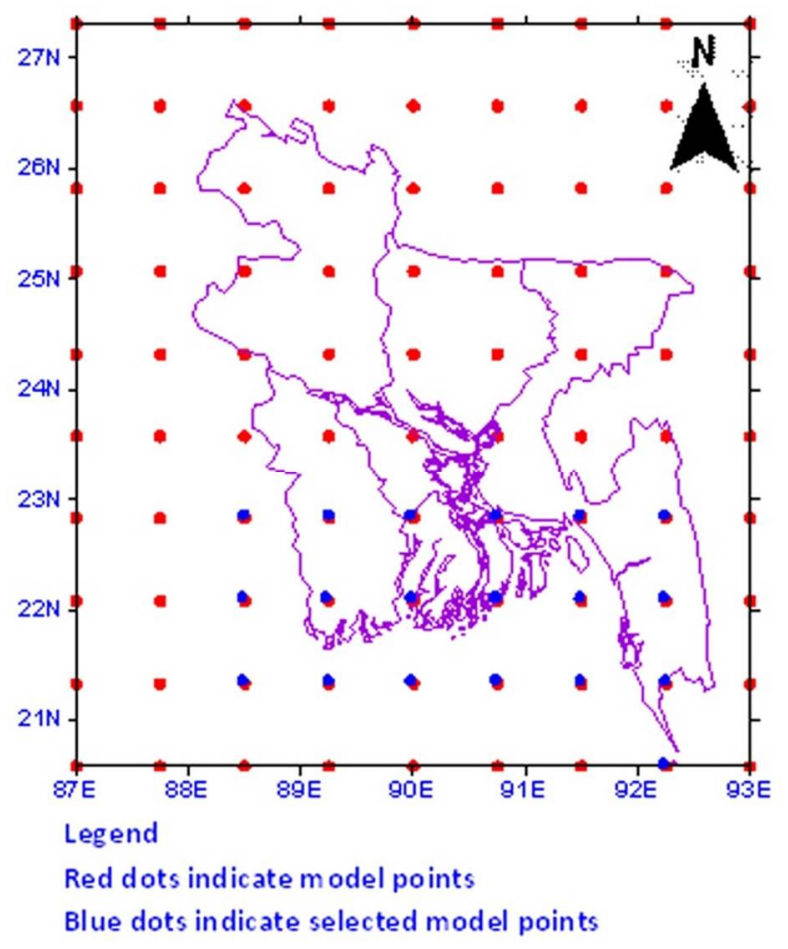

Fig. 2. Coordination maps of CMCC-CM over coastal areas in Bangladesh. 
In this regard, NetCDF format data of selected variables were downloaded from the KNMI (Koninklijk Nederlands Meteorologisch Instituut) website and then cracked the NC file by using R programming. As these data are divided by grid points into the whole world, so picked the data of selected variables according to the appropriate 19 grid points (latitude-longitude) of coastal areas of Bangladesh for 1850 to 2100 (Fig. 2). Basic statistical method was used in this study and the analysis has been conducted based on four specific seasons: winter (December-February), pre-monsoon (March-May), monsoon (June-September) and post-monsoon (October-November); which was followed by different researchers (Islam and Uyeda 2007; Rahman et al. 2017; Shahid 2010) and on an annual basis for CMCC-CM model for both RCPs (4.5 and 8.5) by plotting data in MS Excel and $\mathrm{R}$ programming. The figures are represented by graphs, charts, and WinSurfer, and GIS software was utilized in this research to make a map.

\section{Results and Discussion}

The the study result presents the distribution of the CMCC climate model (for RCP 4.5 and RCP 8.5 scenarios) predicted the rainfall variation by annual and seasonal basis of the coastal areas Bangladesh for the period of 1850-2100.

Annual variation: The annual analysis is represented by Fig. 3a-b, which found that average, median, highest and lowest values of rainfall for both senarios decreased from 1951 to 2000, but it shows an increasing trend afterward up to 2100. Here for RCP 4.5, the average value of rainfall is $1055.62 \mathrm{~mm}, 1094.98 \mathrm{~mm}, 1084.07 \mathrm{~mm}, 1238.43 \mathrm{~mm}$, and $1368.10 \mathrm{~mm}$ during 1850-1900, 1901-1950, 1951-2000, 2001-2050, 2051-2100 respectively. For other scenario RCP 8.5, the average value of rainfall are $1055.62 \mathrm{~mm}$, $1094.98 \mathrm{~mm}, 1084.07 \mathrm{~mm}, 1230.35 \mathrm{~mm}$ and $1569.71 \mathrm{~mm}$ during 1850-1900, 1901-1950, 1951-2000, 2001-2050, 2051-2100, respectively.
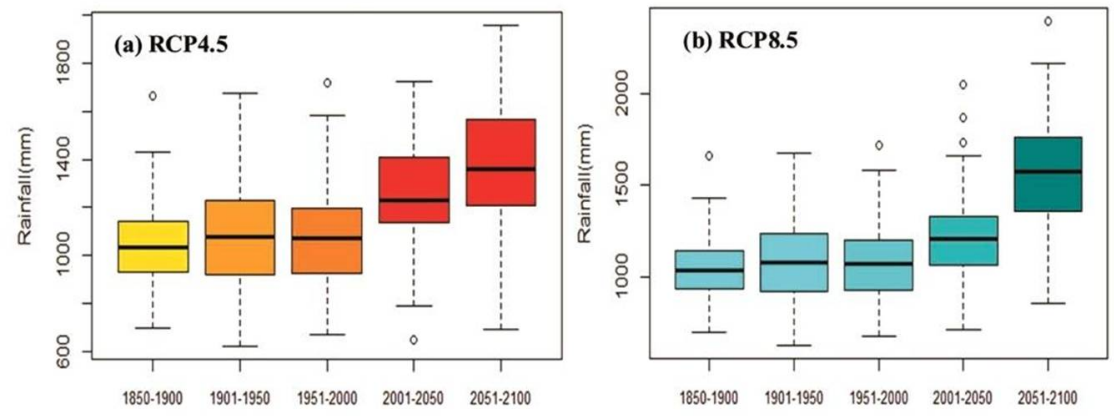

Fig. 3a-b. Variation of annual rainfall derived from CMCC-CM for RCP 4.5 and RCP 8.5 in the study area. 


\section{Seasonal variation}

Summer Season: The total rainfall for the summer season (March to May) for the period of 1850-2100 for both Representative Concentration Pathways (RCPs) is depicted by Fig. $4 a-b$ and found that the average values and lowest values of rainfall for RCP 4.5 decreased from 1951 to 2000 where these values of rainfall for RCP 8.5 decreased from 1951 to 2050, but it shows an increasing trend afterward up to 2100. Similarly, the median values, lowest values and highest values of rainfall are increased in the future. The average rainfall for RCP 4.5 are $69.47 \mathrm{~mm}, 85.05 \mathrm{~mm}, 74.70 \mathrm{~mm}, 78.40 \mathrm{~mm}$ and $94.95 \mathrm{~mm}$ during 1850-1900, 1901-1950, 1951-2000, 2001-2050, 2051-2100, respectively. For RCP 8.5, these are $69.47 \mathrm{~mm}, 85.05 \mathrm{~mm}, 74.70 \mathrm{~mm}, 70.90 \mathrm{~mm}$ and $80.67 \mathrm{~mm}$ during 1850-1900, 1901-1950, 1951-2000, 2001-2050, 2051-2100, respectively. In addition, May was recorded as the highest rainfall month for both RCPs in the summer season (Fig. 5a-b).
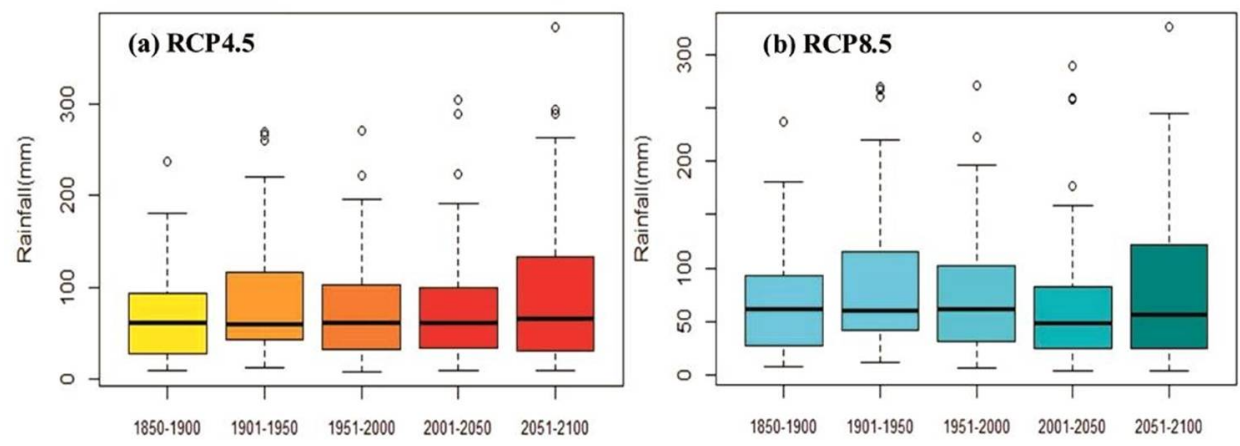

Fig.4 (a-b). Variation of rainfall in summer derived from CMCC-CM for RCP 4.5 and RCP 8.5.
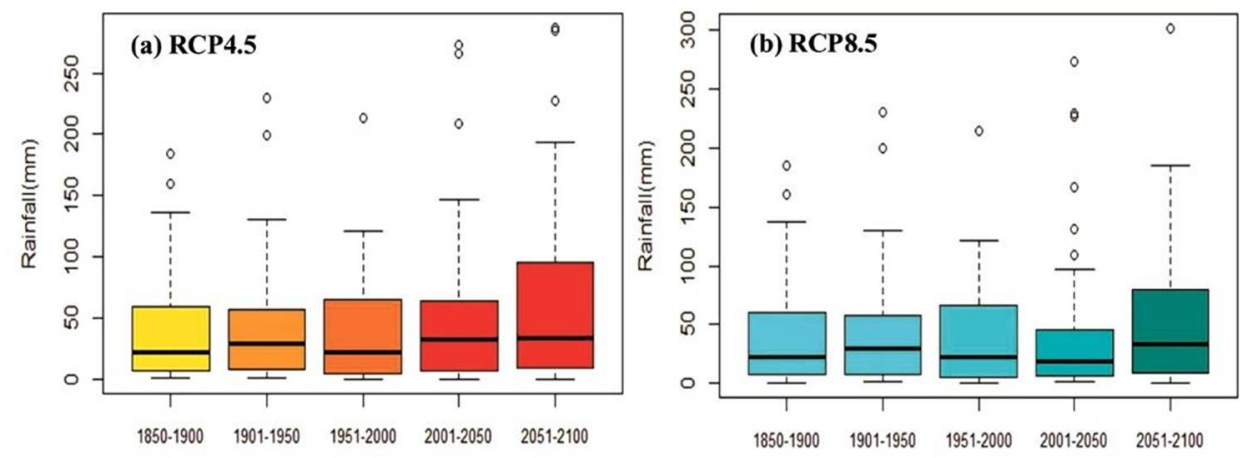

Fig.5 (a-b). Variation of rainfall in May derived from CMCC-CM for RCP 4.5 and RCP 8.5 . 
Monsoon Season: The rainfall for the monsoon season (June to September) for the 250 years is represented by Fig. 6a-b. It shows an increasing trend up to 2100 for the average rainfall values for both RCPs. The average rainfall for RCP 4.5 are 779.51, 786.85, 797.09, 948.63 and $1008.92 \mathrm{~mm}$ during the period of 1850-1900, 1901-1950, 1951-2000, 2001-2050, 2051-2100, respectively. It is found that the median values, highest values, and the lowest values of rainfall for RCP 8.5 decreased from 1901 to1950, but it shows an increasing trend afterward up to 2100 . The average rainfall for this scenario is 779.51 , 786.85, 797.09, 960.33 and $1251.03 \mathrm{~mm}$ during 1850-1900, 1901-1950, 1951-2000, 2001-2050, 2051-2100, respectively. July was the highest rainfall month in the monsoon season for both RCPs (Fig.7a-b).
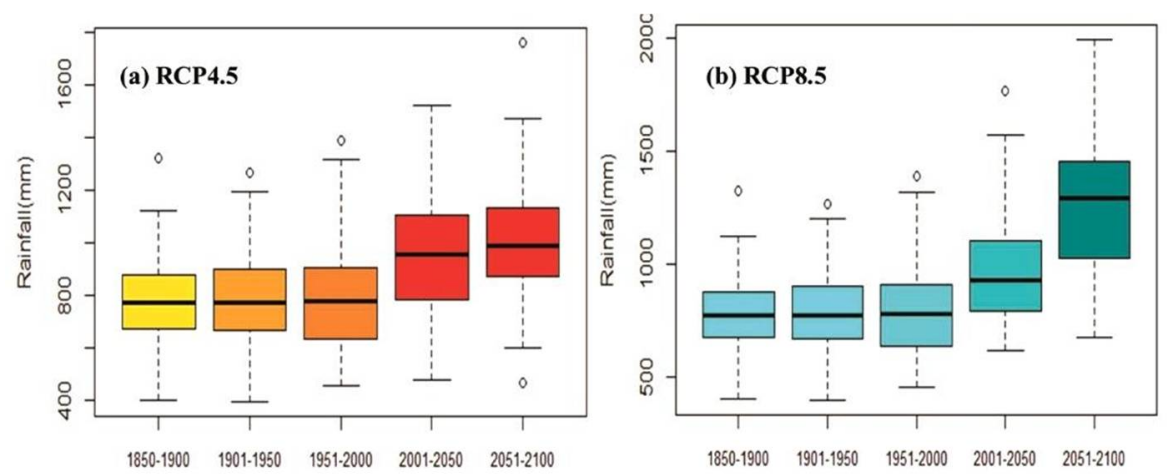

Fig. 6(a-b): Variation of rainfall in Monsoon derived from CMCC-CM for RCP 4.5 and RCP 8.5.
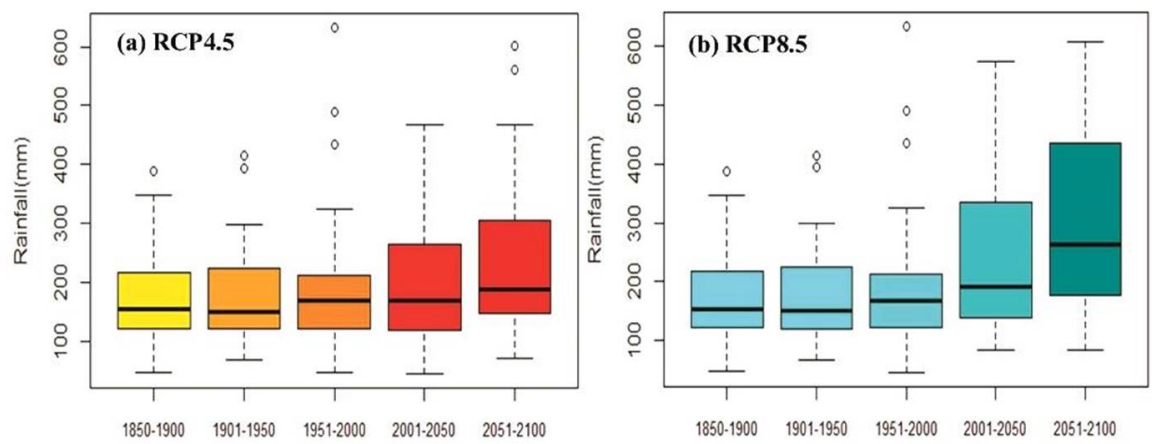

Fig. 7(a-b): Variation of CMCC-CM rainfall in July for RCP 4.5 and RCP 8.5.

Post-monsoon Season: Total rainfall for the post-monsoon season (October to November) of the coastal areas for the baseline period (1850-2100) is represented by Fig. 8a-b. It is found that the average and median values of rainfall for both RCPs decreased from 1951 
to 2050, but it shows an increasing trend afterward up to 2100. Accordingly, the highest and lowest values of rainfall are found to be decreased in the future. Here, the average rainfall for RCP 4.5 are $171.81 \mathrm{~mm}, 185.06 \mathrm{~mm}, 170.14 \mathrm{~mm}, 163.33 \mathrm{~mm}$ and $222.50 \mathrm{~mm}$ during 1850-1900, 1901-1950, 1951-2000, 2001-2050, 2051-2100, respectively. Where, the average rainfall for RCP 8.5 are $171.81 \mathrm{~mm}, 185.06 \mathrm{~mm}, 170.14 \mathrm{~mm}, 154.53 \mathrm{~mm}$ and $215.49 \mathrm{~mm}$ during 1850-1900, 1901-1950, 1951-2000, 2001-2050, 2051-2100 respectively.
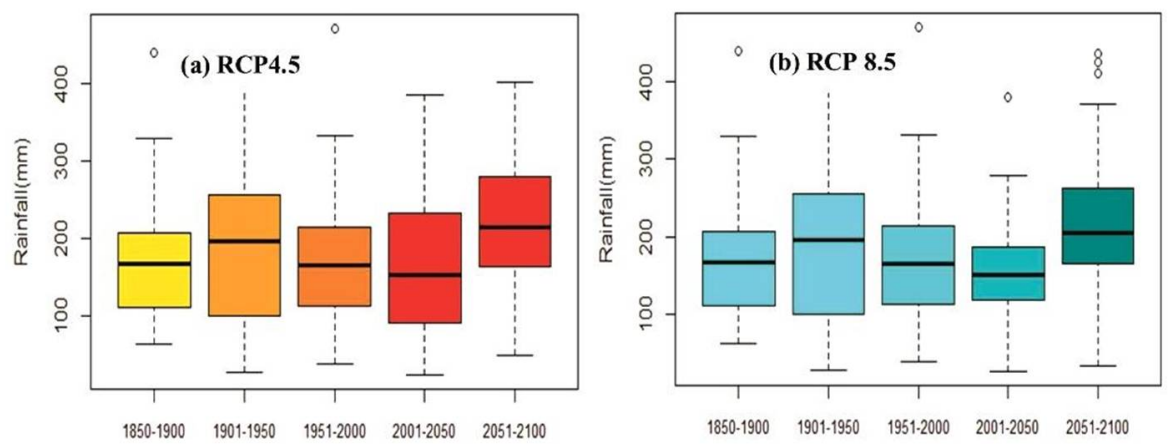

Fig. 8a-b: Variation of rainfall in post-monsoon derived from CMCC-CM for RCP 4.5 and RCP 8.5.

Winter Season: The total rainfall for thewinter season (December to January) for the period of 1850-2100 is represented by Fig. 9a-b and found that the average values of rainfall are increased from 1850 to 2050, but it shows a decreasing trend for both RCPs, afterward up to 2100. Similarly, the median values and highest values of rainfall are found to be decreased in the future for both cases. Furthermore, February was recorded as the highest rainfall month for both scenarios.
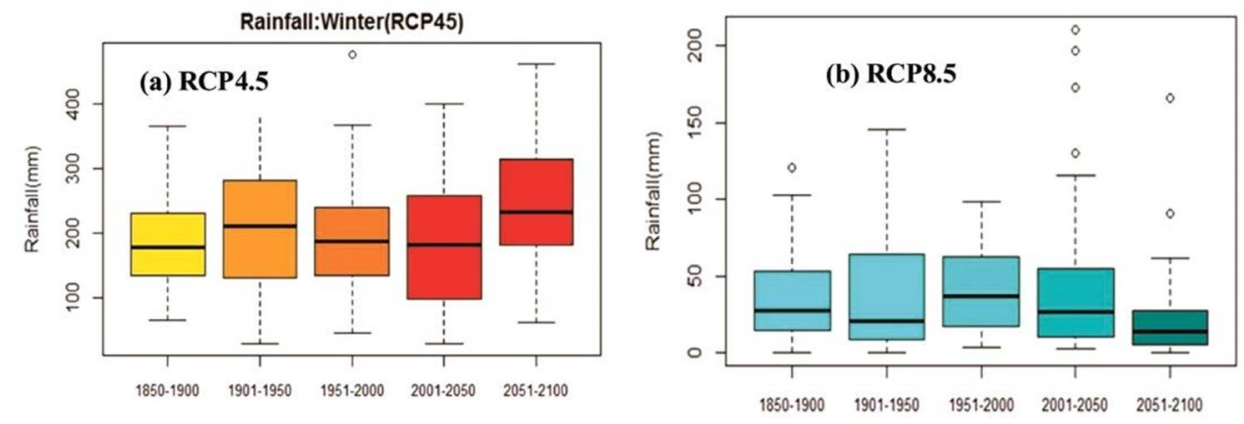

Fig. 9a-b: Variation of rainfall in winter derived from CMCC-CM for RCP 4.5 and RCP 8.5. 


\section{Conclusion}

Bangladesh is considered as one of the most vulnerable countries to the impacts of climate changes (Moniruzzaman 2013). Still the coastal areas are exposed more to climate stresses and stay at a vulnerability front line. Every year Bangladesh faces an average of 1.8 tropical storms (Moniruzzaman and Rashid 2015). However, the casualties in terms of the number of death of people are conspicuously lower than previous experience (Paul et al. 2018). As one of the main elements of climate change is rainfall, these estimations possibly help understand the future climatic conditions and make shortand long-term planning in that area. CMCC-CM model showed an increasing trend of rainfall for both emission scenarios (RCP 4.5 and RCP 8.5) during the baseline period (1850-2100). The annual rainfall has been increased from $1055.62 \mathrm{~mm}$ to $1368.10 \mathrm{~mm}$ from 1850 to 2100 for RCP 4.5, while it has been increased from $1055.62 \mathrm{~mm}$ to 1569.71 $\mathrm{mm}$ for RCP 8.5. In the summer season, rainfall has increased from $69.47 \mathrm{~mm}$ to 94.95 $\mathrm{mm}$ for RCP 4.5, while it has increased to $80.67 \mathrm{~mm}$ for RCP 8.5. Similarly, in the monsoon season, the average rainfall has increased from $779.51 \mathrm{~mm}$ to $1008.92 \mathrm{~mm}$ for RCP 4.5, while it has increased to $1251.03 \mathrm{~mm}$ for RCP 8.5. But in the winter season, the scenario is different. The average rainfall has increased from $35.37 \mathrm{~mm}$ to 41.75 for RCP 4.5, where it has decreased from $35.37 \mathrm{~mm}$ to $22.55 \mathrm{~mm}$ for RCP 8.5 from 1850 to 2100 . It has also been seen that July and February have been recorded as the highest and lowest rainfall month for the monsoon and winter seasons respectively.

From this finding, considering new CMCC-CM (CMIP5) projections will be more helpful for decision-makers as they have a comparatively better representation of the Earth's physical processes. Generally, it shows an increasing trend of rainfall over coastal areas, which indicates more natural calamities in the future. Where the increase is more in high GHGs emission scenarios than the medium. But the rainfall also shows a decreasing trend for the only winter season in the high emission scenario (RCP 8.5), which indicates the barrier of crop productions and reducing groundwater level in the dry season. Consequently, if the GHGs emission can be minimized, the rise of temperature and disparity of rainfall could be controlled but if don't control, the agrarian economy of the coastal area will be more vulnerable.

\section{Acknowledgement}

This research was funded by the Ministry of Science and Technology, Government of Bangladesh, during the 2018-2019 fiscal year. 
Variability of rainfall over the coastal area

\section{References}

Bhuyan, M.D.I., M.M. Islam and M.E.K. Bhuiyan, 2018. A trend analysis of temperature and rainfall to predict climate change for northwestern region of Bangladesh. Amer. J. Climate Change. 7(2): 115-134.

Dore, M. H. 2005. Climate change and changes in global precipitation patterns: what do we know? Environ. Int. 31(8): 1167-1181.

Gemmer, M., S. Becker and T. Jiang. 2004. Observed monthly precipitation trends in China 19512002. Theor. Appl. Climatol. 77(1-2): 39-45.

Harmeling, S. 2008. Global climate risk index 2009 weather-related loss events and their impacts on countries in 2007 and in a long-term comparison. pp. 9.

Haque, M.A., H.A. Quayyum, M.M. Hossain and M.S. Islam. 1992. Occurrence of grain sterility in different rice crops. In International Botanical Conference on Plant Science and Man: Problems and Prospects, Dhaka (Bangladesh), 10-12 Jan 1991. BBS.

Hulme, M., T.J. Osborn, and T.C. Johns. 1998. Precipitation sensitivity to global warming: Comparison of observations with HadCM2 simulations. Geophysical Res. Lett. 25 (17): 33793382.

Islam, M. N., and H. Uyeda. 2007. Use of TRMM in determining the climatic characteristics of rainfall over Bangladesh. Remote Sensing of Environ. 108(3): 264-276.

Islam, S., M. Moniruzzaman and M.A. Mannan. 2019. Estimation of Temperature and Rainfall over Coastal Areas of Bangladesh in a Predicted Climate Change Condition, The J. NOAMI, 36(1-2): 145-156.

KNMI, 2020. Koninklijk Nederlands Meteorologisch Instituut.

Kayano, M. T., and C. Sansígolo. 2009. Inter-annual to decadal variations of precipitation and daily maximum and daily minimum temperatures in southern Brazil. Theor. Appl. Climatol. 97(1-2): 81-90.

Lambert F, P. Stott and M. Allen. 2003. Detection and attribution of changes in global terrestrial precipitation. Geophy. Res. Abst. 5: 06140.

Mannan, MA, F. Rahman, S. Ahmed, M.A.M. Chowdhury, S. Karmakar and M. Moniruzzaman. 2018. Study of Severe Thunderstorm and Associated Rainfall in Bangladesh during Premonsoon Season, DEW-DROP, a Scientific Journal of Meteorology and Geo-Physics. 5(1): 62-71.

Ministry of Water Resources. 2005. Coastal Zone Policy, WARPO, Govt. of Bangladesh, Dhaka.

Moniruzzaman, M. 2012. Geospatial Analysis of Damage, Loss, Recovery and Reconstruction: A Case on Cyclone Sidr, Ph.D. Thesis, Department of Geography and Environment, Jahangirnagar University, Savar, Dhaka, Bangladesh.

Moniruzzaman, M. 2013. People's Perception on Climate Change and Variability: A Study of Sabrang Union, Teknaf, Cox's Bazar, Bangladesh, ASA Univ. Rev. 7(2): 1-10.

Parvin, G.A., S.R. Ahsan and R. Shaw. 2010. Community based coastal zone management in Bangladesh. Communities and Coastal Zone Management, Research Publishing Services, Singapore, 165-184.

Partal, T. and E. Kahya. 2006. Trend analysis in Turkish precipitation data. Hydrol. Processes: An Int. J. 20(9): 2011-2026.

Moniruzzaman, M. and M.S. Rashid. 2015. Spatial Location and Management of Cyclone Shelter: A Case Study on Sarankhola Upazila. Jahangirnagar Review Part II, 35:107-122. 
Paul, P., N. Hawlader and M. Moniruzzaman. 2018. Impacts of Cyclone Mora in Cox's Bazar District, Jagannath Univ. J. Life and Earth Sci. 4(2):124-134.

Rahman, A., M. J.H. Jiban and S. A. Munna. 2015. Regional variation of temperature and Rainfall in Bangladesh: Estimation of Trend. Open J. Statis. 5: 652-657.

Rahman, M.A., S.M. Kamal and M.M. Billah. 2017. Prediction and trends of rainfall variability over Bangladesh. Science J. Appl. Mathematics and Statistics. 5(1): 54-59.

Rahman, M. M., M. N. Islam, A. U. Ahmed and F. Georgi. 2012. Rainfall and temperature scenarios for Bangladesh for the middle of 21st century using RegCM.J. Earth Syst. Sci. 121(2): 287-295.

Rodriguez-Puebla, C., A.H. Encinas, S. Nieto and J. Garmendia. 1998. Spatial and temporal patterns of annual precipitation variability over the Iberian Peninsula. Int. J. Climatol. 18(3): 299-316.

Shahid, S. 2010. Rainfall variability and the trends of wet and dry periods in Bangladesh. Int. J. Climatol. 30 (15): 2299-2313.

Shahid, S. 2011. Trends in extreme rainfall events of Bangladesh. Theor. Appl. Climatol. 104(3-4): 489-499.

Stocker, T.F., D. Qin, G.K. Plattner, M.M. Tignor, S.K. Allen, J. Boschung, A. Nauels, Y. Xia, V. Bex and P.M. Midgley. 2014. Climate Change 2013: The Physical Science Basis. Contribution of working group I of the Fifth Assessment Report (AR5) of IPCC- the Intergovernmental Panel on Climate Change.

Titumir, R.A.M., and J.K. Basak. 2012. Effects of climate change on crop production and climate adaptive techniques for agriculture in Bangladesh. Social Sci. Rev. 29(1): 215-232.

Uddin, A.M.K. and R. Kaudstaal. 2003. Delineation of the Coastal Zone. Program development office for the integrated coastal zone management plan (PDO-ICZMP, Working PaperWP005), Ministry of Water Resources, GoB.

Van Vuuren, D. P., J. Edmonds, M. Kainuma, K. Riahi, A. Thomson, K. Hibbard and T. Masui. 2011. The representative concentration pathways: an overview. Climatic Change, 109:5-31.

Yousuf, A.H.M. 2016. Characteristics of Temperature and Rainfall in Bangladesh: A Historical Perspective 1948-2011. https://ssrn.com/abstract $=3474166$

(Revised copy received on 14.11.2021) 